\title{
The Effect of Immunosuppression on Airway Integrity
}

Hannelore Bellon, $\mathrm{MSc}^{1}$, Elly Vandermeulen, $\mathrm{PhD}^{1}$, Stijn E Verleden, $\mathrm{PhD}^{1}$,

Tobias Heigl, MSc ${ }^{1}$, Hanne Vriens, $\mathrm{MSc}^{2}$, Elise Lammertyn, $\mathrm{MSc}^{1}$, Lieve Verlinden, $\mathrm{PhD}^{3}$, Thomas Vanhove, $\mathrm{MD}^{4}$, Mieke Verstuyf, $\mathrm{PhD}^{3}$, Peter Hoet, $\mathrm{PhD}^{2}$, Robin Vos, $\mathrm{MD}^{1}$, Geert M Verleden, $\mathrm{MD}, \mathrm{PhD}^{1}$, Bart M Vanaudenaerde, $\mathrm{PhD}^{1}$

${ }^{1}$ Lung Transplant Unit, Division of Respiratory Disease, Department of Clinical and Experimental Medicine, KULeuven, Leuven Belgium.

${ }^{2}$ Environment and Health, KULeuven, Leuven Belgium.

${ }^{3}$ Clinical and Experimental Endocrinology, KULeuven, Leuven Belgium.

${ }^{4}$ Department of Microbiology and Immunology, Laboratory of Neprhology, KULeuven, Leuven Belgium.

Address for correspondence:

Prof Bart Vanaudenaerde

Lab of respiratory diseases

Box 706, Herestraat 49

3000 Leuven, Belgium

bart.vanaudenaerde@kuleuven.be 


\section{AUTHORSHIP PAGE}

HB: research design, data acquisition, statistical analysis, writing of the manuscript

EV: data acquisition, critical appraisal of the manuscript

SEV: participated in research design, participated in the writing of the paper, critical appraisal of the manuscript

TH: critical appraisal of the manuscript

HV: data acquisition, critical appraisal of the manuscript

EL: critical appraisal of the manuscript

LV: data acquisition, critical appraisal of the manuscript

TV: critical appraisal of the manuscript

MV: data acquisition, critical appraisal of the manuscript

PH: participated in research desing, critical appraisal of the manuscript

$\mathrm{RV}$ : participated in research design, participated in the writing of the paper, critical appraisal of the manuscript GMV: participated in research design, participated in the writing of the paper, critical appraisal of the manuscript BMV: participated in research design, participated in the writing of the paper, critical appraisal of the manuscript

None of the authors have anything to disclose. 


\section{LIST OF ABBREVIATIONS}

$16 \mathrm{HBE}$

Human Bronchial Epithelial cells

CLAD Chronic Lung Allograft Dysfunction

EMT Epithelial to mesenchymal transition

FCS $\quad$ Fetal calf serum

HLMVEC Human Lung Microvascular Endothelial cells

HPLC-MS/MS High pressure liquid chromatography-mass spectrometry

IL-8 Interleukin-8

ISHLT International Society for Heart and Lung Transplantation

LC-MS/MS Liquid chromatography-mass spectrometry

LTx Lung transplantation

MMF Mycophenolate mofetil

TEER Trans-epithelial electrical resistance 


\section{ABSTRACT}

Background: Insults to the airway epithelium play a key role in constrictive bronchiolitis following lung transplantation (LTx), the typical hallmark of chronic rejection. Our hypothesis is that immunosuppressives might affect airway integrity.

Methods: A biculture of lung bronchial epithelial cells (16HBE) and lung microvascular endothelial cells (HLMVEC) was exposed to immunosuppressives (serum through levels) for $24 \mathrm{~h}$ or 4 days. Cytotoxicity, trans-epithelial electrical resistance (TEER) and permeability was measured after exposure to monotherapies and combination therapies. Apoptosis, oxidative stress, inflammation (IL-8), real time PCR for epithelial-to-mesenchymal-transition (EMT) and tight junction proteins were assessed in exposed cells.

Results: MMF and combination therapies including MMF, at serum trough levels and higher, are toxic for the 16HBE cells after 4 days exposure. Moreover, already after $24 \mathrm{~h}$, TEER of cells exposed to MMF decreases and permeability increases. MMF did not induce apoptosis, oxidative stress, loss of tight junctions or production of IL-8 after $24 \mathrm{~h}$, but possibly induces EMT in epithelial cells. MMF was detectable at both sides of the biculture and was also present in broncho-alveolar-lavage (BAL) of LTx patients. Other immunosuppressives were not toxic, neither changed TEER or permability.

Conclusions: Our findings suggest that MMF is present in the airways of lung transplant patients and might affect the structural integrity of the airway, which needs further investigation and validation in the clinical setting. 


\section{INTRODUCTION}

Lung transplantation (LTx) is the ultimate treatment option for patients with end-stage lung diseases. Survival after LTx remains poor with a median survival of 5.7 years, mainly due to chronic lung allograft dysfunction $(\mathrm{CLAD})^{1}$. The 2 phenotypes of CLAD recognized so far (restrictive allograft syndrome and bronchiolitis obliterans syndrome) show typical airway lesions on pathology, being constrictive bronchiolitis, which is small airway obliteration because of inflammation and subsequent fibrosis. Besides constrictive bronchiolitis lesions on histology, restrictive allograft syndrome is also characterized by persistent infiltrates on chest CT scan, which represent interstitial inflammation and/or fibrosis on histology. ${ }^{2,3}$. Chronic injury to the airway epithelium is believed to lead to an excessive immune response, overproduction of extracellular matrix and subsequent complete obliteration of the airway lumen $^{4}$.

The causes of these injuries are only partly known. A possible mechanism is epithelial-to-mesenchymal-transition (EMT) in which bronchial epithelial cells transition to (myo)fibroblasts ${ }^{5,6}$, thereby gaining properties of mesenchymal cells, including production of matrix metalloproteinases and deposition of extracellular matrix ${ }^{5}$.

To prevent CLAD, a triple drug regimen is used including a calcineurin inhibitor (cyclosporine (C) or tacrolimus (T)), antiproliferative agents (azathioprine (A) or mycophenolate mofetil (MMF or M) and corticosteroids (like dexamethasone (D)) ${ }^{7}$. The most used triple drug regimen in our centre is a combination of dexamethasone-azathioprinecyclosporine or dexamethasone-MMF-tacrolimus. Per the International Society of Heart and Lung Transplantation (ISHLT), the most used combination therapy at 1 year and 5 years after adult lung transplantation (LTx) is corticosteroids-MMF-tacrolimus, however long-term survival for this treatment and for the treatment regimen corticosteroids-MMF-cyclosporine is 
worse compared to the treatment regimens without MMF and with azathioprine as antiproliferative agent ${ }^{14}$.

Our hypothesis is that classical immunosuppressive drugs, used to control the immune system, may negatively affect the bronchial epithelium, contributing to constrictive bronchiolitis. Zacharias et al, for example, demonstrated a cytotoxic effect of high doses of mycophenolic acid in human retinal cells. Neuringer et al, demonstrated that both acute and chronic cyclosporine treatment of tracheobronchial epithelial cell cultures inhibited growth at clinically relevant concentrations ${ }^{6,8,9}$.

Our current in vitro research approach is to use cell lines of structural lung cells resembling the airway, allowing the study of the direct effects of the immunosuppressive drugs on airway integrity, using a biculture of human bronchial epithelial cells (16HBE) and lung microvascular endothelial cells (HLMVEC).

\section{MATERIAL AND METHODS}

\section{Cell culture}

Human Bronchial Epithelial cells, 16HBE14o- (16HBE) (provided by Dr. Gruenert, University of California, San Fransisco, USA) and Human Lung microvascular endothelial cells (HLMVEC) were purchased from the European Collection of Cell Cultures (Salisbury, UK) and cultured as previously described ${ }^{10}$. $16 \mathrm{HBE}$ cells were used for experiments between passages 3-15, HLMVEC cells between passages 3-10. N-values of 6 were used (2 different passages of cells, 3 replicates per passage). 


\section{Biculture setup}

To mimic the barrier between blood stream and epithelium of the lung (ie, to mimic drug delivery of immunosuppressive drugs to the lungs via the blood), a biculture of $16 \mathrm{HBE}$ cells and HLMVEC cells was set up as described in Luyts et al. ${ }^{10}$ (Figure S1, SDC, http://links.lww.com/TP/B446). When the medium of both compartments was renewed at day 1, 4 and 7, the supernatant of both compartments was collected $(200 \mu \mathrm{L})$. The biculture was allowed to grow for 4 days, to reach submaximal Trans Epithelial Electrical Resistance (TEER), before experiments were started ${ }^{10}$.

\section{Immunosuppressive drugs}

Immunosuppressive agents were dissolved in dimethyl sulfoxide (DMSO) for azathioprine, ethanol for dexamethasone, tacrolimus and cyclosporine or acetone for MMF. Agents or their appropriate vehicle control were added. In all experiments, DMSO, ethanol or acetone never exceeded $0.1 \%$ as a final concentration in culture media. Immunosuppressive drugs cyclosporine, MMF, azathioprine and dexamethasone were purchased from SigmaAldrich (Bornem, Belgium). Tacrolimus (FK506) was kindly provided by Astellas Pharma Belux (Anderlecht, Belgium). For C, T and MMF, serum trough levels and levels 10 times lower and 10 times higher were tested. Trough levels were defined based on clinically targeted patients' trough levels (Table S1, SDC, http://links.lww.com/TP/B446). As serum trough levels are not determined for $\mathrm{A}$, a concentration of $0.5 \mu \mathrm{g} / \mathrm{mL}$ was used in our experiments, based on the product information of Imuran. For dexamethasone, levels used were in accordance with daily doses used in human LTx recipients. Monotherapies as well as triple drug regimens were tested. The cells in the biculture set up were exposed via the basolateral compartment (endothelial side) (Figure S1, SDC, http://links.lww.com/TP/B446). 


\section{Cytotoxicity assays}

To mimic acute and chronic exposure, exposure for $24 \mathrm{~h}$ or 4 days respectively to the immunosuppressive drugs was performed.

Upon reaching submaximal TEER, cells were exposed via the basolateral compartment to medium containing $0.2 \%$ FCS supplemented with different concentrations of immunosuppressive drugs. After an incubation period of 24 hours or 4 days, the cytotoxic effect of immunosuppressive drugs on 16HBE cells was assessed, using a WST-1 assay as described in Luyts et al. ${ }^{10}$

To confirm cytotoxicity, a LDH assay (ThermoFisher Scientific, Merelbeke, Belgium) was performed. Therefore, 15000 16HBE cells were seeded into a 96 well-plate and incubated overnight in $37^{\circ} \mathrm{C}$ in a $100 \%$ humidified atmosphere containing $5 \% \mathrm{CO}_{2}$. Cells were than exposed to MMF (0-0.25-2.5-25 $\mu \mathrm{g} / \mathrm{mL})$ for $24 \mathrm{~h}$ or 4 days. As LDH released into the supernatant is measured, medium was not changed for the 4 days exposure, but fresh medium was added after 2 days. LDH assay was performed per manufacturer's instructions.

\section{Trans-epithelial electrical resistance (TEER)}

TEER was measured using the EVOM ${ }^{2}$ voltohmmeter with the STX2 electrode as described in the instruction manual of the EVOM2 meter (World Precision Instruments, Inc., Berlin, Germany). Corrections for the surface area were made.

\section{Permeability assay}

A permeability assay was performed on bicultures exposed to MMF for $24 \mathrm{~h}$. After $24 \mathrm{~h}$ exposure with MMF, FITC-dextran (4 kDa) (ThermoFischer Scientific) was added to the epithelial side at a final concentration of $1 \mathrm{mg} / \mathrm{mL}$. Cells were incubated 4 hours in the dark. 
Afterwards, medium from the basolateral compartment was transferred to a black 96 wellplate and the amount of FITC-dextran that passed through the biculture was measured with a fluorescence multi-well plate reader (FluoStar Omega, BMG Labtech, Ortenberg, Germany) (excitation and emission wavelengths: $485 \mathrm{~nm}$ and $530 \mathrm{~nm}$, respectively).

\section{Epithelial-to-mesenchymal transition (EMT)}

A monoculture of $16 \mathrm{HBE}$ cells was exposed to MMF $(2.5 \mu \mathrm{g} / \mathrm{mL})$ when confluency was reached. After $24 \mathrm{~h}$ or 4 days exposure, RNA extraction was performed. Cells were lysed with Trizol Reagent (Thermo Fischer Inc.) and RNA was extracted via Phenol-chloroform Extraction per manufacturer's instructions (Qiagen, Venlo, The Netherlands). Amount of RNA was measured via NanoDrop (Isogen Life Science, Utrecht, The Netherlands). A human EMT PCR Array (Qiagen), looking at the expression of 84 key genes that either change their expression during EMT or regulate those gene expression changes, was performed per the manufacturer's instructions $(n=3)$. Analysis of the assay was performed using the $\Delta \Delta \mathrm{Ct}$ method. Corrections for multiple testing were performed using the 'false discovery rate' test in the statistical program $\mathrm{R}$.

To confirm epithelial-to-mesenchymal transition, also measurements of E-cadherin (Assay biotech, Sunnyvale, USA) and vimentin (Abnova, Germany) levels in exposed and unexposed cells were done via sandwich ELISA on cell lysate after $24 \mathrm{~h}$ or 4 days exposure to $2.5 \mu \mathrm{g} / \mathrm{mL}$ MMF according to manufacturer's instructions. Samples were diluted 1/50 for the E-cadherin ELISA. For the vimentin ELISA, samples were not diluted.

\section{In vitro and in vivo measurements of immunosuppressives in BAL}

The prodrug MMF was added to the cells, and the active drug mycophenolic acid (MPA) was measured. To test whether MPA could translocate to the epithelial cells, MPA in 
the supernatant at both sides of the biculture was measured using high throughput HPLCMS/MS. Similarly, MPA was measured using HPLC-MS/MS in BAL of stable lung transplant patients (10 patients taking MMF vs. 10 patients not taking MMF) and tacrolimus was measured with an immuno-assay method and LC-MS/MS method on the Waters TQD LC-MS/MS, performed in the Clinical Laboratory of the University Hospital Leuven (5 patients taking tacrolimus vs. 5 not taking tacrolimus). Briefly, BAL is performed with 2 aliquots of sterile saline $(50 \mathrm{~mL})$ of which the returned fractions were pooled and centrifuged 11.

\section{Statistical Analysis}

Graph prism 4.0 software (San Diego, CA, USA) was used for statistical analysis. Results are presented as mean \pm SEM and analyzed using the MANN-Whitney U-test. A p < 0.05 was considered statistically significant.

\section{RESULTS}

\section{MMF impairs epithelial integrity}

None of the tested immunosuppressive drugs (tacrolimus, cyclosporine, azathioprine, MMF or dexamethasone) were toxic for the epithelial cells in biculture at trough levels after an acute exposure of $24 \mathrm{~h}$ (Figure 1A). After a chronic exposure of 4 days, only MMF was toxic for the cells (viability $<80 \%$ ) at trough levels and concentrations 10 times higher (Figure 1A).

To validate cytotoxicity, an LDH assay on $16 \mathrm{HBE}$ cells was performed after $24 \mathrm{~h}$ or 4 days exposure to MMF. This test showed similar results as the WST-1 assay: no toxicity after 24h exposure to MMF, but after 4 days of exposure to MMF, LDH in the supernatant increased significantly starting from a concentration of $2.5 \mu \mathrm{g} / \mathrm{mL}$, which is indicative of cytotoxicity (Figure 1B). 
Although there was no toxic effect of MMF after 24h exposure, TEER was significantly lower after $24 \mathrm{~h}$ compared to control cells (Figure 1A) and permeability was also higher (Figure 1C). TEER for the bicultures exposed to the other immunosuppressive drugs did not decrease after 24h (Figure 1A).

Also, combination therapies (dexamethasone-cyclosporine-azathioprine, dexamethasone-tacrolimus-MMF, dexamethasone-cyclosporine-MMF and dexamethasonetacrolimus-azathioprine) were tested. Combination therapies including MMF showed the same results as MMF alone (ie, no toxicity after $24 \mathrm{~h}$ exposure, but toxicity after chronic exposure of 4 days). Combination of dexamethasone-cyclosporine-MMF was borderline toxic at trough levels and higher, while the combination dexamethasone-tacrolimus-MMF was already toxic for epithelial cells at trough levels (Figure S2A and S2B, SDC, http://links.lww.com/TP/B446). Although there was no toxic effect after 24h exposure, TEER was significantly lower for cells exposed to combination therapies including MMF, compared to unexposed cells (Figure S2C and S2D, SDC, http://links.lww.com/TP/B446). Combination therapies without MMF were not toxic for cells after acute or chronic exposure and TEER did not decrease after $24 \mathrm{~h}$ exposure (data not shown).

To investigate the effect of MMF on epithelial cells, we performed multiple experiments (see online supplement, SDC, http://links.lww.com/TP/B446). We demonstrated that MMF had no effect on apoptosis (Figure S3, SDC, http://links.lww.com/TP/B446), IL-8 or 8-isoprostane concentration (Figure S4 and S5, SDC, http://links.lww.com/TP/B446), nor on loss of tight junction proteins (ZO-1 and occludin) (Figure S6, SDC, http://links.lww.com/TP/B446) after 24h exposure, compared to control cells. 


\section{EMT}

Without correction for multiple testing, human EMT PCR Array after 24h exposure showed significant ( 2 fold) upregulation of 9 genes, and a nonsignificant trend for 3 other genes, involved in EMT. Also, 1 gene normally down regulated during EMT, was significantly down regulated compared to unexposed cells (Table S2, SDC, http://links.lww.com/TP/B446). After correction for multiple testing, however, none of the genes remained statistically significant.

In contrast, the same assay performed after 4 days exposure showed significant upregulation of 11 genes (VIM, MAP1B, MMP3, SNAI2, CALD1, CAMK2N1, FOXC2, BMP7, BMP2, ZEB1, PLEK2) involved in EMT after correction for multiple testing. Also, 2 genes (CDH2 and COL5A2) showed a nonsignificant trend. One gene (FGFBP1) normally down regulated during EMT, was significantly down regulated compared to unexposed cells and there was a nonsignificant trend for 2 other genes (KRT14 and DSC2). Furthermore, there were also genes (DESI1, ITGB1) that were significantly upregulated or down-regulated of which we know they are involved in EMT, but it is at present not clear what their function in EMT is and if they should be down- or upregulated for EMT to be present. There were also 2 genes (TMEFF1 and RGS2) that acted in the opposite way as expected for EMT. RGS2 was upregulated in the EMT PCR assay, but should be down regulated in EMT and TMEFF1 was down regulated in the assay and should be up regulated during EMT (Figure 2 A and B, Table S2, SDC, http://links.lww.com/TP/B446).

Genes were mainly involved in differentiation and development, migration and motility, formation of the cytoskeleton and extracellular matrix and cell adhesion. 
To validate our findings, we also performed an ELISA to measure the protein levels of E-cadherin and vimentin in cell lysate of the epithelial cells exposed to serum trough levels of MMF for $24 \mathrm{~h}$ or 4 days. All samples were below detection limits for the vimentin ELISA (data not shown). For E-cadherin, after 24h exposure, there is no difference in E-cadherin levels of MMF exposed compared to unexposed cells, but after 4 days exposure, E-cadherin levels are significantly lower in MMF exposed compared to unexposed cells (Figure 2C).

\section{Translocation of MMF}

To test the translocation of the active drug, MPA, from the endothelial to the epithelial side, we measured MPA at both sides of the biculture. MPA was detected in the supernatant at epithelial side at an average concentration of $50.9 \mathrm{ng} / \mathrm{mL} \pm 5.9 \mathrm{ng} / \mathrm{mL}$ (Figure 3A), while MPA in the supernatant at the endothelial side had an average concentration of $122.8 \mathrm{ng} / \mathrm{mL} \pm$ $8.2 \mathrm{ng} / \mathrm{mL}$. (Figure 3B).

In LTx patients receiving MMF, MPA was detectable in BAL samples with an average of $3.9 \mathrm{ng} / \mathrm{mL} \pm 1.3 \mathrm{ng} / \mathrm{mL}$ (Figure $3 \mathrm{C}$ ), which was significantly higher compared to patients not taking MMF $(\mathrm{p}<0.0001)$. There was, however, no correlation between serum trough levels and concentration MPA measured in BAL. Also, tacrolimus was detected in the BAL samples of patients taking tacrolimus, although at a very low concentration $(0.21 \mathrm{ng} / \mathrm{mL} \pm 0.02$ $\mathrm{ng} / \mathrm{mL}$ ). Tacrolimus concentrations in BAL samples of LTx patients not taking tacrolimus were below detection limit.

\section{DISCUSSION}

To our knowledge, this is the first in vitro study investigating the direct effect of immunosuppressive agents and combination therapies on a biculture of human bronchial epithelial cells and lung microvascular endothelial cells. 
MMF at trough levels, although not toxic for epithelial cells after an exposure of $24 \mathrm{~h}$, significantly impairs epithelial integrity, while 4 days exposure to trough levels of MMF or higher concentrations, severely decreased viability. None of the other tested immunosuppressive drugs showed toxicity after $24 \mathrm{~h}$ or 4 days exposure. Therefore, we further focused on possible mechanisms of MMF-induced impairment of the bronchial epithelium, but could not demonstrate a role for apoptosis, tight junction proteins ZO-1 and occludine, oxidative stress or inflammation (see online supplement, SDC, http://links.lww.com/TP/B446). However, we found evidence that EMT might be (at least partially) responsible for decreased epithelial integrity, occurring possibly already after $24 \mathrm{~h}$ but clearly visible after 4 days exposure.

Indeed, our results suggest that MMF evokes EMT in 16HBE epithelial cells, which allows epithelial cells to migrate through the underlying basement membrane and to accumulate in the interstitium of the tissue, where they ultimately dispose all their epithelial markers and gain a fully fibroblastic phenotype ${ }^{3,12}$. On the one hand, already after $24 \mathrm{~h}$, different genes involved in EMT were differently expressed in MMF exposed cells compared to unexposed cells. However, after correction for multiple testing, no significance was reached for these genes. After 4 days, on the other hand, even after correction for multiple testing, 16 genes were differentially regulated, suggesting that MMF can evoke EMT. However, we acknowledge that there are also 2 genes (TMEFF1 and RGS2) differentially expressed in the opposite way, which would favor against EMT. However, given the large majority of differentially expressed genes supports the EMT hypothesis, together with the Ecadherin results, we suspect that MMF could evoke EMT.

It is already known that bronchial epithelial cells undergo EMT when stimulated with TGF- $\beta 1^{5}$. Although, TGF- $\beta 1$ is seen as the main orchestrator of the remodeling process of the 
airways after LTx, it has been described that air pollutants and immunosuppressive drugs can also induce $\mathrm{EMT}^{3}$.

Moreover, Felton et al, showed that rat bronchial epithelial cell line (RL-65) can undergo partial EMT due to cyclosporine or MMF, with loss of cell-cell adhesions and upregulation of fibronectin and vimentin expression ${ }^{6}$. There may be several reasons why we did not see EMT following cyclosporine exposure: first, cells in the study of Felton et al, were exposed apically, whereas our cells were exposed at the basolateral side of the biculture setup. We suspect that not all the cyclosporine is able to cross the endothelial barrier and the membrane before exerting its effects. Moreover, Felton et al, used a rat cell line in their study, which shows a difference in drug absorption, movement of drugs from the interstitium to blood, plasma/serum protein composition, plasma protein binding which limits extrapolation from rat to human ${ }^{14}$. We did not look at EMT for cyclosporine as we did not see an effect on cytotoxicity or TEER when cells were exposed to cyclosporine. A study of Tomei et al, performed in human type II pneumocyte derived A549 and 2 bronchial cell lines also looked at EMT of these cells after exposure to tacrolimus or everolimus. Doses of tacrolimus were comparable with our study andf did not induce EMT. They, however, observed dosedependent effects of everolimus on these cells, also pointing out the importance of administering the right dosage and avoiding, wherever possible, drug over-exposure ${ }^{15}$. Since we only rarely use everolimus in our hospital and wordwide use is also limited, we did not investigate the effects of everolimus in our model. There is also another study by Copeland et al, performed on proximal tubular epithelial cells that demonstrated an inhibitory effect of MMF on EMT in vitro ${ }^{16}$. They concluded that MMF may result in less fibrosis and a better long-term survival. However, concentrations they used to expose the cells with were between 1 and $50 \mathrm{ng} / \mathrm{mL}$, which is much lower than we used in our experiments $(2.5 \mu \mathrm{g} / \mathrm{mL})$. We choose to use a concentration like the serum through levels to accurately reflect the in vivo situation. 
In other organs, similar deleterious effects of MMF were shown as Qasim et al, used Caco-2 (epithelial colorectal) cells to investigate the effects of MMF ${ }^{17}$. They demonstrated that MMF concentrations used (although higher than in our study) did not cause significant apoptosis or cell death. However, TEER of Caco-2 cells exposed to MMF decreased and tight junctions disappeared together with appearance of increased paracellular openings between adjacent cells after 72 hours ${ }^{17}$. With a concentration of MMF 40 times higher than the amount we used, Zacharias et al, showed an increase in caspase-3/7 activity in ARPE-19 (retinal pigment epithelium) cells ${ }^{8}$.

The active form of MMF, MPA could be detected at both sides of the biculture, proving that MPA is present at the epithelial side after exposure of the endothelial side of the biculture to the prodrug MMF. Whether it is the prodrug MMF or its active compound MPA that is able to cross the endothelial/epithelial barrier cannot be concluded based on this study. Moreover, even in vivo, we could detect MPA in BAL fluid of LTx patients. The presence of MPA in the BAL fluid proves that MPA, and its metabolites, are present in the airway lumen and can exert deleterious effects on the airway epithelium. To our knowledge, this is the first time that MPA could be detected in BAL samples of LTx recipients. We also tested if other immunosuppressive agents could translocate to the epithelium and indeed we detected the presence of tacrolimus in BAL-fluid of LTx patients, although at a very low concentration (average of $0.208 \mu \mathrm{g} / \mathrm{L}$, below detection limit). We acknowledge that concentration measured below detection limit is not accurate, but there was no peak visible at the retention time of tacrolimus for patients not taking tacrolimus (control) and there was a clear peak for patients taking tacrolimus, however with a low concentration. This provides proof that tacrolimus is present in the BAL fluid of patients. We suspect that the high dilution factor of BAL is the cause of the very low concentrations found and the fact that there is a lower trough level of tacrolimus compared to MMF (10 ng/mL compared to $2.5 \mu \mathrm{g} / \mathrm{mL})$ in patients. 
The amount of MPA and other agents found in BAL is much lower compared to what is found in serum, which is probably a dilution effect as the instilled fluid is mixed with the epithelial lining fluid. Determination of the percentage of epithelial lining fluid and hence the concentration of constituents in this epithelial lining fluid is therefore difficult. ${ }^{18,19}$. The amount of MPA found in the BAL samples therefore does not reflect the amount of MPA that can be found in the epithelial lining fluid. However, the fact that MPA can be found in BAL of these patients does prove that at least the active form of MMF, MPA can transmigrate into the airway lumen and encounters airway epithelial cells. If it is the prodrug MMF that transmigrates into the airway lumen or its active component MPA cannot be concluded based on our experiments.

One of the limitations of our study is that we used cell lines instead of primary cells. However, we specifically chose to use a cell line because we wanted to establish large scale experiments which are producible and physiological relevant. It has been described that the risk of infections and contamination for cell lines is much lower than for primary cells; variability is lower, reproducibility is higher and more standardized and controlled results can be achieved. Another limitation of our study is that we used serum trough levels of immunosuppressive drugs to expose our cells with. This is probably not the exact number of immunosuppressive drugs that reaches the epithelial cells, given that serum peak levels may be much higher. To our knowledge, the concentration of immunosuppressive drugs present in the epithelial lining fluid has not been studied yet. To take this into account, we also tested concentrations 10 times higher than these serum trough levels.

Although MMF was toxic on cell culture at trough levels and is detectable in BAL fluid, patient outcome, nevertheless, demonstrates no difference in incidence of acute rejection, chronic rejection or overall survival between MMF and azathioprine treatment ${ }^{20}$. 
Moreover, MMF can prevent acute and chronic rejection by suppression of the recipient's immune system. Maybe it is only in the very long run (survival $>5$ years) that chronic MMF exposure towards the structural cells starts to play a role, which needs further investigation. However, our findings might open a discussion about the dose of MMF given to LTx patients and raises questions of current overdosing MMF to transplant patients, which could be prevented with therapeutic drug monitoring of MMF.

In conclusion, we found that MMF could decrease the epithelial integrity, possibly by EMT. These findings need further attention and consideration given the wide-spread use of MMF to transplant patients.

\section{ACKNOWLEDGMENTS}

SEV and RV are sponsored by FWO (12G8715N and $1803516 \mathrm{~N})$. RV is supported by the Research Foundation Flanders (FWO) (KAN2014 1.5.139.14) and UZ Leuven (STG15/023). GMV and BMV are supported by the FWO (G.0723.10 and G.0679.12) and KU Leuven research funding C24/15/030. None of the authors have anything to disclose in relation to this study. 


\section{REFERENCE LIST}

1. Lund LH, Edwards LB, Kucheryavaya AY, et al. The Registry of the International Society for Heart and Lung Transplantation: Thirtieth Adult Lung and Heart-Lung Transplant Report--2013; focus theme: age. J Heart Lung Transplant. 2013; 32(10):95164.

2. Ofek E, Sato M, Saito T, et al. Restrictive allograft syndrome post lung transplantation is characterized by pleuroparenchymal fibroelastosis. Mod Pathol. 2013; 26(3):350-356.

3. Royer PJ, Olivera-Botello G, Koutsokera A, et al. Chronic lung allograft dysfunction: a systematic review of mechanisms. Transplantation. 2016; 100(9):1803-1814.

4. Elssner A, Vogelmeier C. The role of neutrophils in the pathogenesis of obliterative bronchiolitis after lung transplantation. Transpl Infect Dis. 2001; 3(3):168-176.

5. Borthwick LA, Parker SM, Brougham KA, et al. Epithelial to mesenchymal transition (EMT) and airway remodelling after human lung transplantation. Thorax. 2009; 64(9):770-777.

6. Felton VM, Inge LJ, Willis BC, Bremner RM, Smith MA. Immunosuppression-induced bronchial epithelial-mesenchymal transition: a potential contributor to obliterative bronchiolitis. J Thorac Cardiovasc Surg. 2011; 141(2):523-530.

7. Scheffert JL, Raza K. Immunosuppression in lung transplantation. J Thorac Dis. 2014; 6(8):1039-1053.

8. Zacharias LC, Damico FM, Kenney MC, et al. In vitro evidence for mycophenolic acid dose-related cytotoxicity in human retinal cells. Retina. 2013; 33(10):2155-2161.

9. Neuringer IP, Sloan J, Budd S, et al. Calcineurin inhibitor effects on growth and phenotype of human airway epithelial cells in vitro. Am J Transplant. 2005; 5(11):26602670.

10. Luyts K, Napierska D, Dinsdale D, Klein SG, Serchi T, Hoet PH. A coculture model of the lung-blood barrier: the role of activated phagocytic cells. Toxicol In Vitro. 2015; 
29(1):234-241.

11. Vos R, Vanaudenaerde BM, Geudens N, Dupont LJ, Van Raemdonck DE, Verleden GM. Pseudomonal airway colonisation: risk factor for bronchiolitis obliterans syndrome after lung transplantation? Eur Respir J. 2008; 31(5):1037-1045.

12. Kalluri R, Weinberg RA. The basics of epithelial-mesenchymal transition. J Clin Invest. 2009; 119(6):1420-1428.

13. Lamouille S, Xu J, Derynck R. Molecular mechanisms of epithelial-mesenchymal transition. Nat Rev Mol Cell Biol. 2014; 15(3):178-196.

14. Martinez, MN. Factors influencing the use and interpretation of animal models in the development of parenteral drug delivery systems. AAPS J. 2011; 13(4):632-649.

15. Tomei P, Masolva V, Granata S, et al. Everolimus-induced epithelial to mesenchymal transition (EMT) in bronchial/pulmonary cells: when the dosage does matter in transplantation. J Nephrol. 2016; 29(6):881-891.

16. Copeland JW, Beaumont BW, Merrilees MJ, Pilmore HL. Epithelial-to-mesenchymal transition of human proximal tubular epithelial cells: effects of rapamycin, mycophenolate, cyclosporin, azathioprine, and methylprednisolone. Transplantation. 2007; 83(6):809-814.

17. Qasim M, Rahman H, Ahmed R, Oellerich M, Asif AR. Mycophenolic acid mediated disruption of the intestinal epithelial tight junctions. Exp Cell Res. 2014; 322(2):277-289.

18. Baughman RP. Technical aspects of bronchoalveolar lavage: recommendations for a standard procedure. Semin Respir Crit Care Med. 2007; 28(5):475-485.

19. Baughman RP. The uncertainties of bronchoalveolar lavage. Eur Respir J. 1997; 10(9):1940-1942.

20. McNeil K, Glanville AR, Wahlers T, et al. Comparison of mycophenolate mofetil and azathioprine for prevention of bronchiolitis obliterans syndrome in de novo lung transplant recipients. Transplantation. 2006; 81(7):998-1003. 


\section{FIGURE LEGENDS}

Figure 1: A. Cytotoxic effect of immunosuppressive agents (cyclosporine, tacrolimus, MMF, azathioprine and dexamethasone) on a biculture of 16HBE cells and HLMVEC endothelial cells after 24 hours or 4 days. Trough levels and concentrations 10 times higher and 10 times lower were used. Cytotoxicity is defined as a viability below $80 \%$ compared to control. TEER measurement of the epithelial cells in the biculture exposed to trough levels of the immunosuppressive agents for 24 hours. The solid line represents the TEER of control cells and the dashed line represents the TEER of the cells exposed to the immunosuppressive agents. TEER measured right before exposure was set as reference (100\%). N=6 (2 different passages of cells, 3 replicates per experiment). B. LDH assay for $16 \mathrm{HBE}$ cells exposed to MMF for 24h (left) and 4 days (right). $n=12$ ( 2 different passages, 6 replicates per passage). C. Permeability assay on biculture after addition of MMF at the HLMVEC side for $24 \mathrm{~h}$. Flux of 4KDa FITC dextrans is shown, expressed as a percentage compared to control cells. ***: $\mathrm{p}<0.01$, Mann-Whitney U-test. N=6 (2 different passages of cells, 3 replicates per experiment).

Figure 2: A. Genes upregulated or downregulated in the real-time PCR EMT assay and their function after 4 days exposure to MMF. The grey colored genes are borderline significant. A $\mathrm{p}$ value $<0.05$ is significant; Statistical test used is 'False Discovery Rate' to correct for multiple testing. B. Heat map of the genes that were significantly differently expressed in MMF exposed cells compared to control cells. Blue: genes that are upregulated. Red: genes that are down regulated. Black: genes involved in EMT, but not mentioned to be up- or down regulated in the assay. There is 1 gene, RGS2, that is up regulated and should be down regulated for EMT. There is also 1 gene, TMEFF1 that is upregulated in the assay and should be down-regulated for EMT. N=3. C. Validation of EMT via E-cadherin ELISA for cells 
exposed to MMF for $24 \mathrm{~h}$ or for 4 days. *: $\mathrm{p}<0,05$; Mann-Whitney U-test, $\mathrm{n}=9$ (3 different passages of cells, 3 replicates per passage).

Figure 3: Concentration of the active drug mycophenolic acid (MPA) (ng/mL) present in supernatant of 16HBE side of the biculture (A) $(n=6)$, the supernatant of HLMVEC side of the biculture after exposure to $2.5 \mu \mathrm{g} / \mathrm{mL}$ of the prodrug MMF (B) (n=6) and in BAL of patients $(\mathrm{C})(\mathrm{n}=10)$, measured via high throughput HPLC-MS/MS. *: $\mathrm{p}<0.05$, ***: $\mathrm{p}<$ 0.0001; Mann-Whitney U-test. 
A
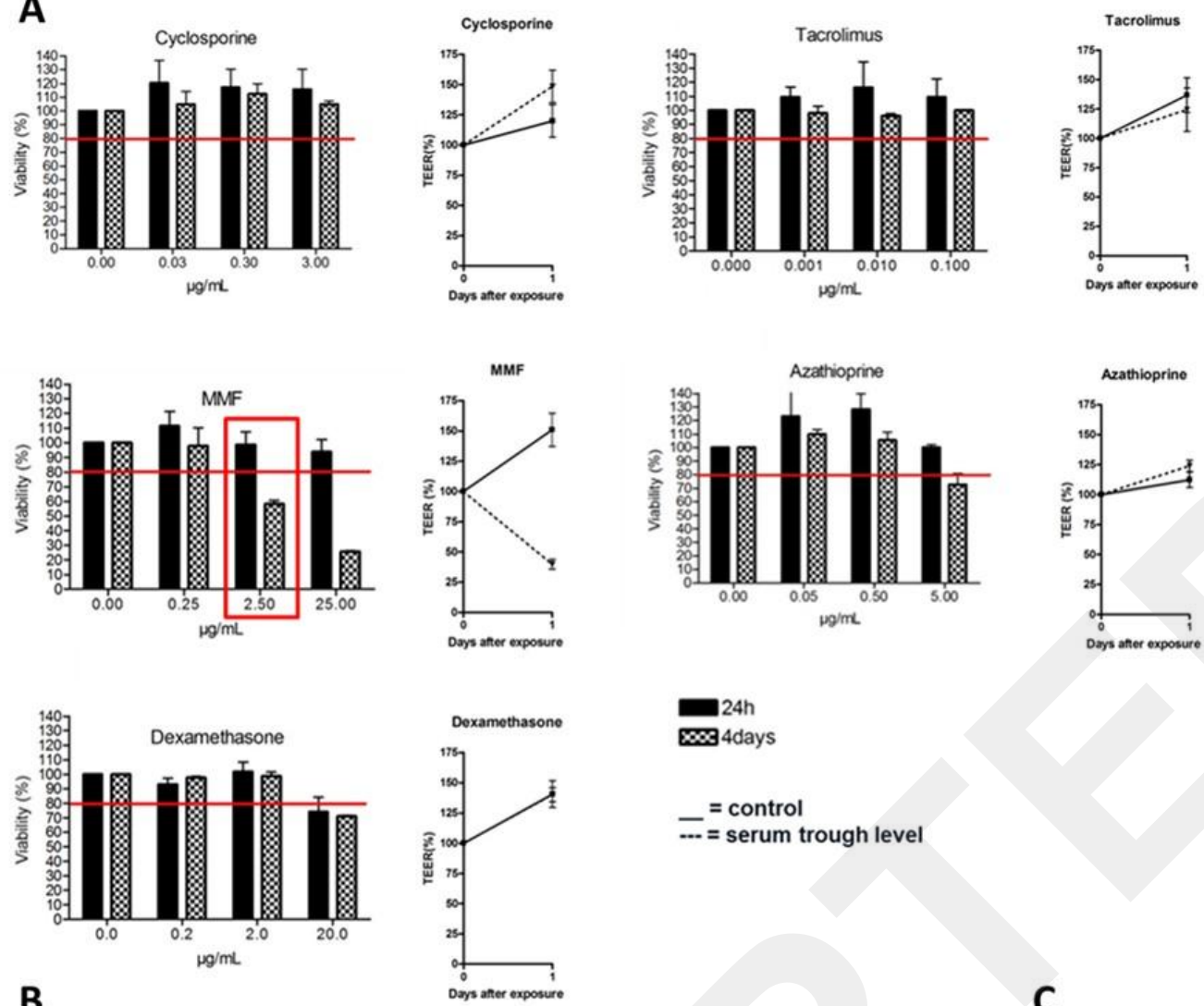

$\cos 4$ days

B
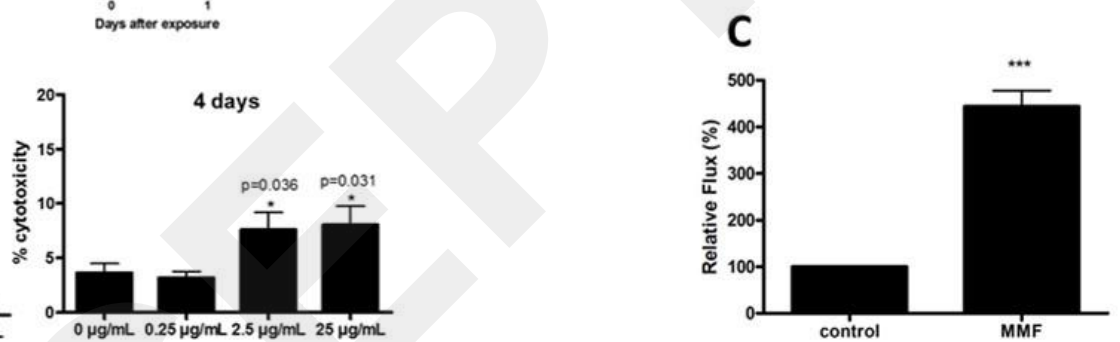
A

\begin{tabular}{|cccc|}
\hline Upregulated during EMT & Function & Fold upregulation vs. control & p-value \\
\hline VIM & Cytoskeleton & 12.70 & 0.03 \\
MAP1B & Cytoskeleton & 3.35 & 0.008 \\
MMP3 & Extracellular matrix \& cell adhesion & 4.34 & 0.02 \\
SNAI2 & Transcription factor & 3.82 & 0.003 \\
CALD1 & Migration \& motility & 2.52 & 0.05 \\
CAMK2N1 & Protein kinase inhibitor & 2.48 & 0.03 \\
FOXC2 & Extracellular matrix \& cell adhesion & 3.53 & 0.05 \\
BMP7 & Cell growth \& proliferation & 5.03 & 0.04 \\
BMP2 & Cell growth \& proliferation & 23.41 & 0.008 \\
ZEB1 & Transcription factor & 6.00 & 0.05 \\
PLEK2 & cytoskeleton & 1.46 & 0.04 \\
\hline CDH2 & Extracellular matrix \& cell adhesion & 3.77 & 0.09 \\
COLSA2 & Differentiation \&Development & 2.98 & 0.08 \\
\hline Downregulated during EMT & Function & Fold downregulation vs. control & p-value \\
\hline FGFBP1 & Cell growth \& proliferation & 7.06 & 0.03 \\
\hline KRT14 & Differentiation \& development & 3.34 & 0.053 \\
OSC2 & Extracellular matrix \& cell adhesion & 1.75 & 0.09 \\
\hline
\end{tabular}

C E-cadh 24h

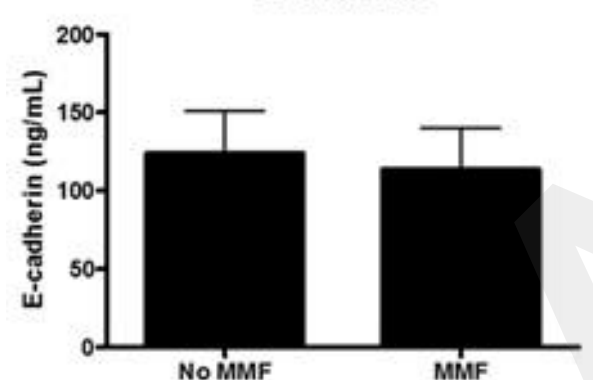

No MMF

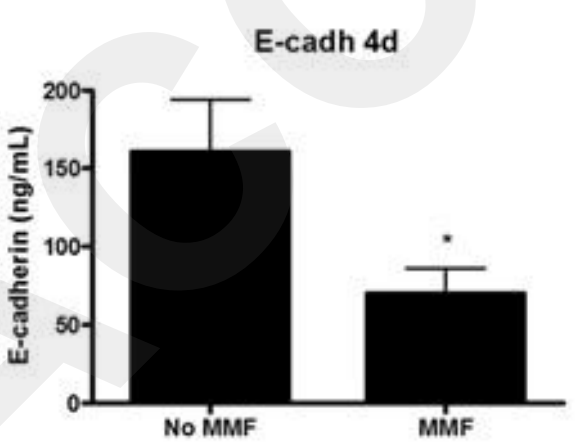

B

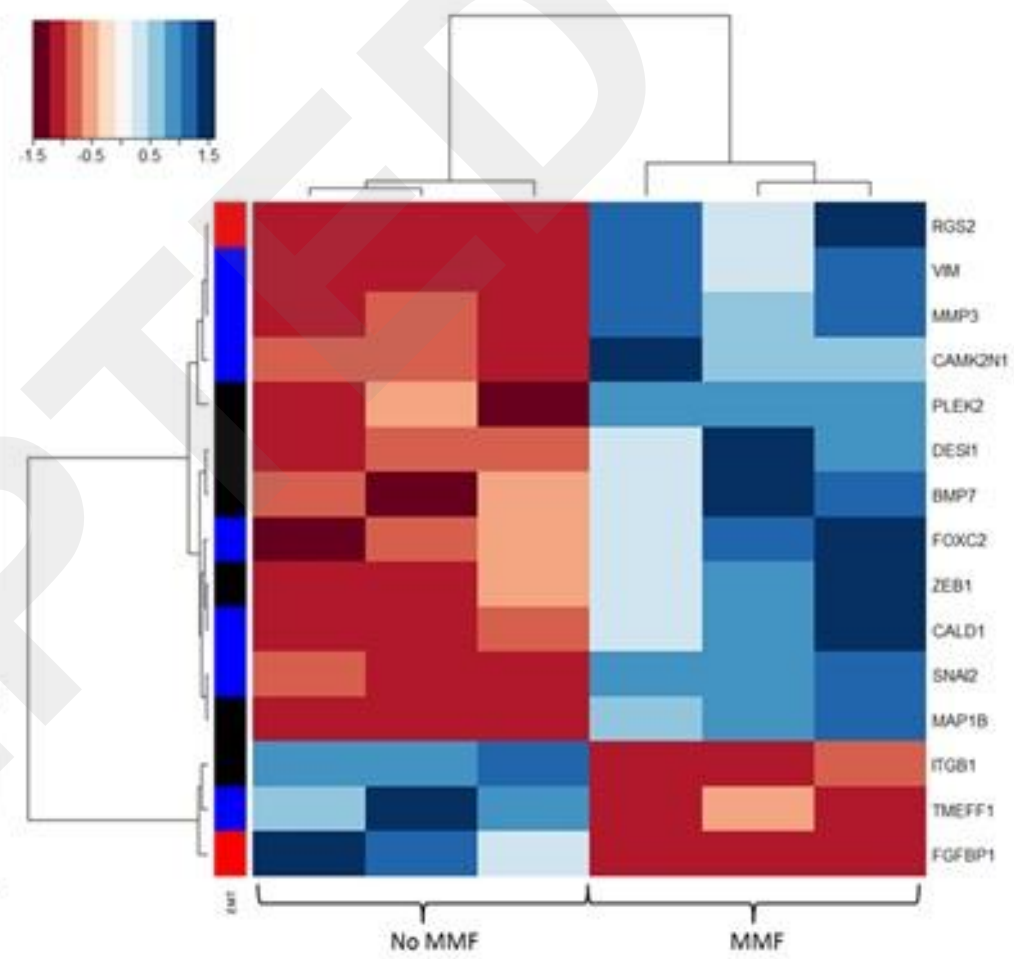



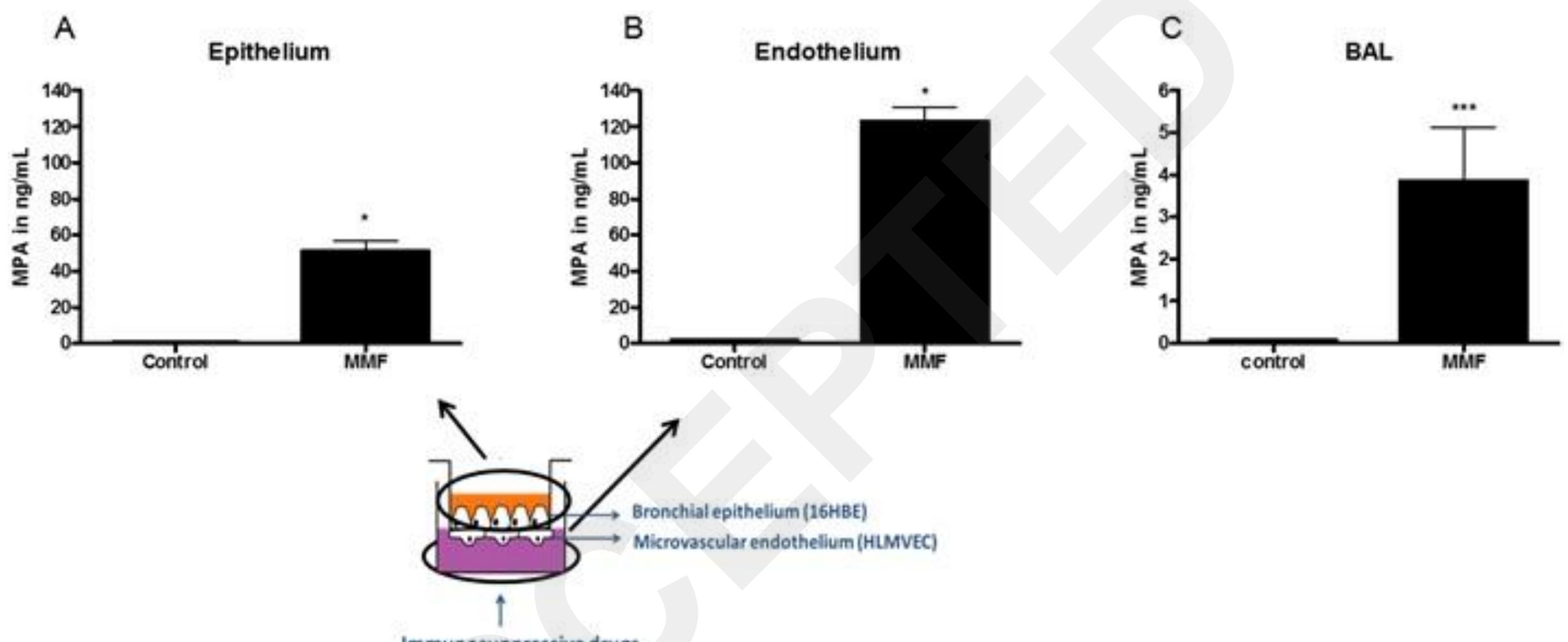

Immunosuppressive drugs 


\section{Online supplement}

\section{MATERIALS AND METHODS}

\section{Apoptosis assays}

Using the biculture, after $24 \mathrm{~h}$ (acute) and 4 days (chronic) exposure to serum through levels of MMF, supernatant of epithelial cells was collected and centrifuged for $10 \mathrm{~min}$ to pellet detached cells. The cells still attached to the biculture, were rinsed twice with ice cold DPBS. Afterwards, $200 \mu \mathrm{L}$ cell extraction buffer (ThermoFisher Scientific) supplemented with $1 \mathrm{mM}$ Phenylmethylsulfonyl fluoride and 1 tablet PhosSTOP (Roche) was added to the epithelial side of the biculture. After scraping cells, cell extraction buffer containing scraped cells was added to the pelleted detached cells and vortexed. Samples were stored in $-80^{\circ} \mathrm{C}$ until the start of the ELISA for caspase 3 (ThermoFisher Scientific). The APO-1/FAS/CD95 ELISA (ThermoFisher Scientific) was performed on cell culture supernatant that was collected after $24 \mathrm{~h}$ exposure. ELISA's were performed according to the manufacturer's instructions Using a $1 / 5$ sample dilution for caspase 3 and $1 / 2$ for APO1/FAS/CD95.

\section{IL-8 release and oxidative stress (8-isoprostane)}

After exposure for 1, 4 and 7 days, IL-8 (CXCL8) and 8-isoprostane release in culture media of the apical (16HBE cells) and the basolateral (HLMVEC cells) compartment of the biculture were determined via sandwich ELISA (Invitrogen) and competitive ELISA (Cayman Chemical, Michigan, USA) respectively. ELISA was performed per manufacturer's instructions. Cell culture supernatant was diluted $1 / 5$ and $100 \mu \mathrm{L}$ was used.

\section{Tight junction proteins (ZO-1 and occludine)}

Bicultures of 16HBE epithelial cells and HLMVEC endothelial cells were exposed to MMF for 24 hours or 72 hours (in this case, medium was changed once and new MMF was added) at serum concentration $(2.5 \mu \mathrm{g} / \mathrm{mL})$ at the endothelial side of the membrane. After incubation, immunofluorescent staining, as described by Luyts et al, on the biculture membrane was performed with the Alexa Fluor 488-labeled mouse antihuman ZO-1 antibody and the Alexa Fluor 594-labeled mouse antihuman Occludin antibody (ThermoFisher Scientific) ${ }^{9}$. Nuclei were counterstained with 4',6-diamino-2-phenylindole (DAPI) (ThermoFisher Scientific). Only epithelial cells were stained. A confocal microscope was used to visualize the stainings (Leica SP8x). 


\section{RESULTS}

\section{MMF does not induce apoptosis, oxidative stress or inflammation}

Cells exposed to MMF for $24 \mathrm{~h}$ or 4 days were tested for apoptosis via APO-1/FAS in supernatant of epithelial cells in biculture and caspase-3 on cell lysate of epithelial cells from the biculture. APO-1/FAS was below detection limit for all tested samples (data not shown). For the active caspase-3 assay, there was no difference between controls and MMF treated cells (Figure S3).

The results of the 8-isoprostane ELISA are shown in Figure S4. After 4 days of exposure to MMF, 8-isoprostane levels seem to be decreased compared to cells without exposure to MMF. However, we could clearly see under the microscope that cells exposed to MMF after $24 \mathrm{~h}$ began to release from the culture flask. Medium of the cells exposed to MMF for 4 days was renewed after 2 days. Therefore, the released cells were washed out and less cells were still present on the insert. This explains the drop in 8-isoprostane compared to cells without MMF exposure. We could therefore not conclude that there is a difference in 8-isoprostane levels for MMF exposed cells compared to unexposed cells.

The results of the IL- 8 measurements are shown in Figure S5. It can clearly be see that there is no difference in IL 8 between exposed and nonexposed cells.

\section{ZO-1 and occludine staining on biculture}

The decrease in TEER of bicultures (and hence barrier function) exposed to MMF for 24 hours, could not be explained by a decrease in tight junction expression. However, after $24 \mathrm{~h}$, the tight junction proteins ZO-1 and occludine (Figure S6) were unchanged. There was no clear difference between control cells and cells exposed to MMF throughout the whole surface of the stained insert. For the staining of tight junction proteins ZO-1 and occludine 72 hours after exposure with MMF, clear differences between MMF-exposed cells and control cells were seen, as cells exposed to MMF had detached, consequently tight junctions had disappeared, and regions without cells were present (data not shown). 


\section{FIGURE LEGEND}

Figure S1: In vitro set up of a biculture of human bronchial epithelial cells (16HBE; apical side) and human lung microvascular endothelial cells (HLMVEC; basolateral side). Immunosuppressive agents are added at the basolateral side.

Figure S2: A. Viability assay of combination therapy dexamethasone-tacrolimus-MMF on the biculture after $24 \mathrm{~h}$ or 4 days exposure. B. Viability assay of the combination therapy dexamethasone-cyclosporine-MMF on biculture after $24 \mathrm{~h}$ or 4 days exposure. C. TEER measurement of cells exposed to dexamethasone-tacrolimusMMF at trough levels for 24h. D. TEER measurement of cells exposed to dexamethasone-cyclosporine-MMF at trough levels for $24 \mathrm{~h}$. Cytotoxicity is defined as a viability below $80 \%$ compared to control. TEER measured right before exposure was set as reference (100\%). $\mathrm{N}=6$ (2 different passages of cells, 3 replicates per experiment). *: $p<0.05$; Mann-Whitney U-test. 0: control, 1: 1/10 serum trough levels, 2: serum trough levels, 3: 10x serum trough levels.

Figure S3: Active Caspase 3 apoptosis assay on 16HBE cells in a biculture after exposure of $24 \mathrm{~h}$ to the serum trough level of MMF (2,5 $\mu \mathrm{g} / \mathrm{mL})$. $\mathrm{N}=6$ ( 2 different passages of cells, 3 replicates per experiment).

Figure S4: 8-isoprostane ELISA on the supernatant of 16HBE cells in biculture with HLMVEC cells after $24 \mathrm{~h}$ and 4 days. Cells exposed to MMF were exposed to serum trough levels of MMF $(2.5 \mu \mathrm{g} / \mathrm{mL})$. Exposure was on the HLMVEC side of the biculture.

Figure S5: IL-8 ELISA on the supernatant of 16HBE cells in biculture with HLMVEC cells after $24 \mathrm{~h}$ and 4 days. Cells exposed to MMF were exposed to serum trough levels of MMF $(2.5 \mu \mathrm{g} / \mathrm{mL})$. Exposure was on the HLMVEC side of the biculture.

Figure S6: Staining of the 16HBE cells on the insert in biculture with HLMVEC cells for nonexposed cells (left) or after exposure to $2.5 \mu \mathrm{g} / \mathrm{mL}$ MMF for $24 \mathrm{~h}$ (right). The blue color is DAPI and the green color is ZO- 1 protein. 


\section{FIGURES}

Figure S1:

\section{In vivo}
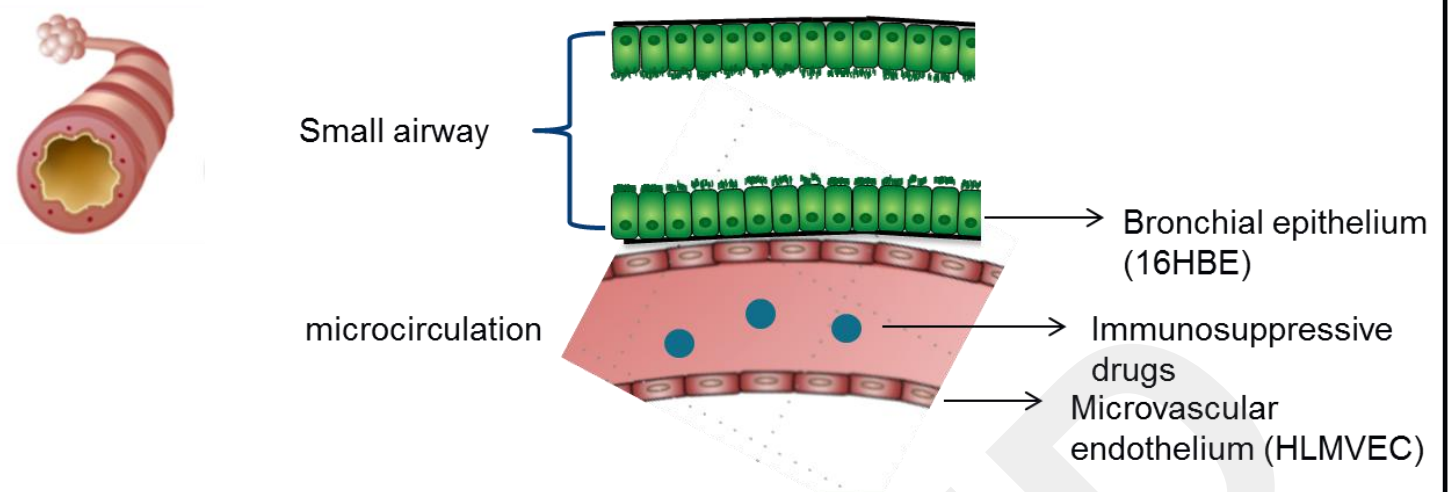

In vitro

Bronchial epithelium (16HBE)

Microvascular endothelium (HLMVEC)

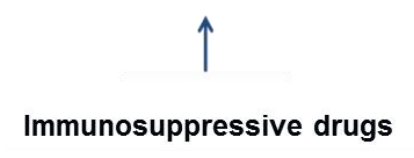

- Calcineurin inhibitor: Tacrolimus or Cyclosporine

- Antimetabolite: Azathioprine or Mycophenolate Mofetil

- Corticosteroid: Dexamethasone

- Combination therapies 
FIGURE S2:
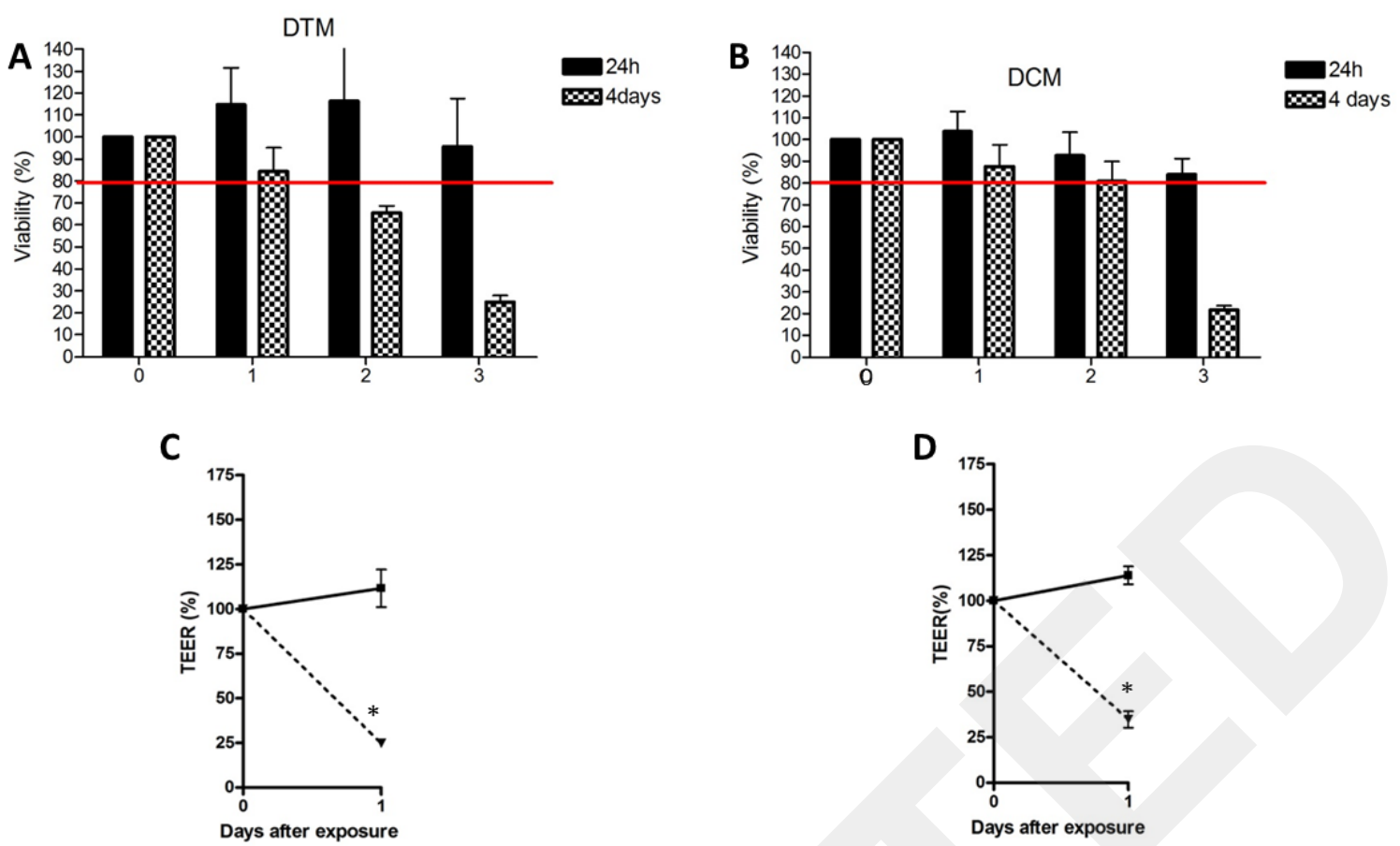
FIGURE S3:

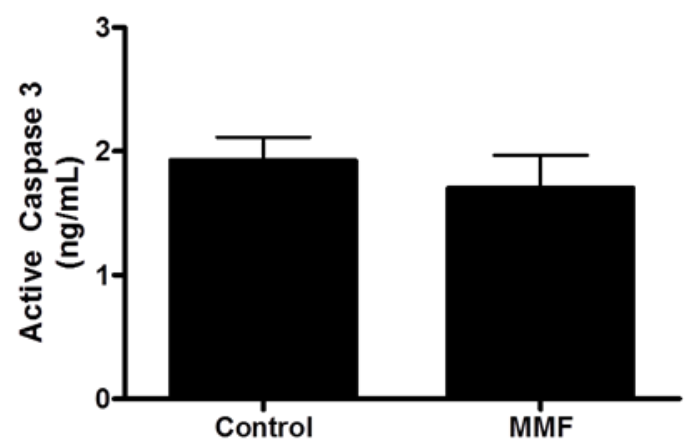

FIGURE S4:
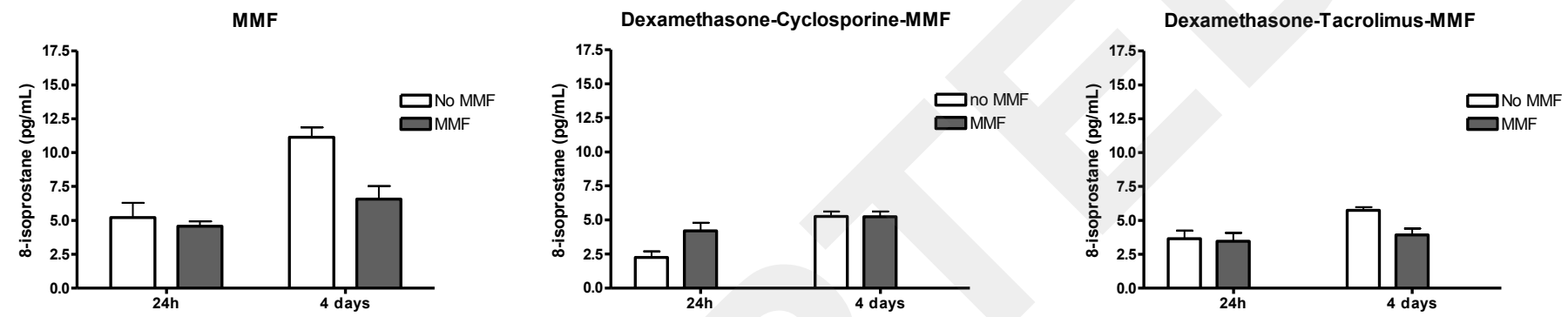

FIGURE S5:
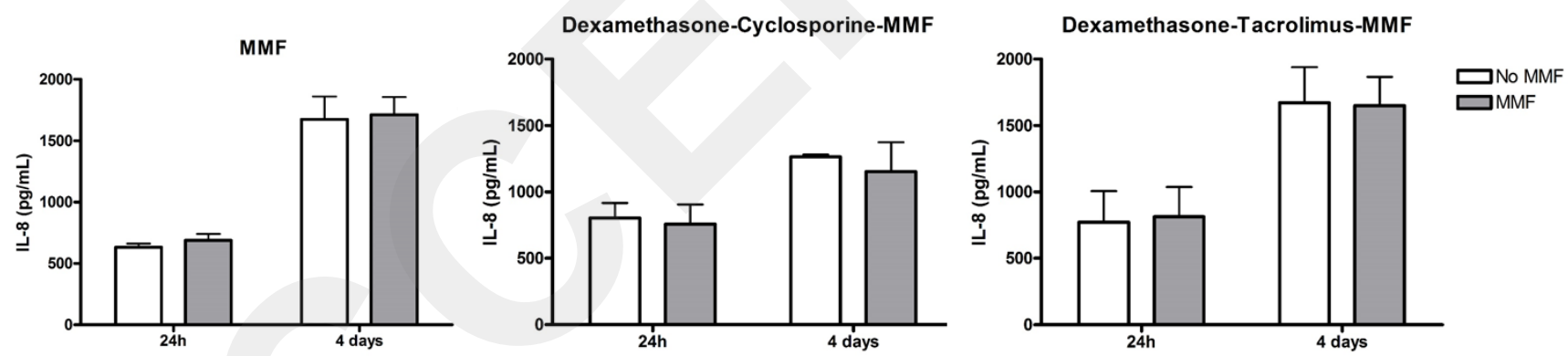


\section{FIGURE S6:}
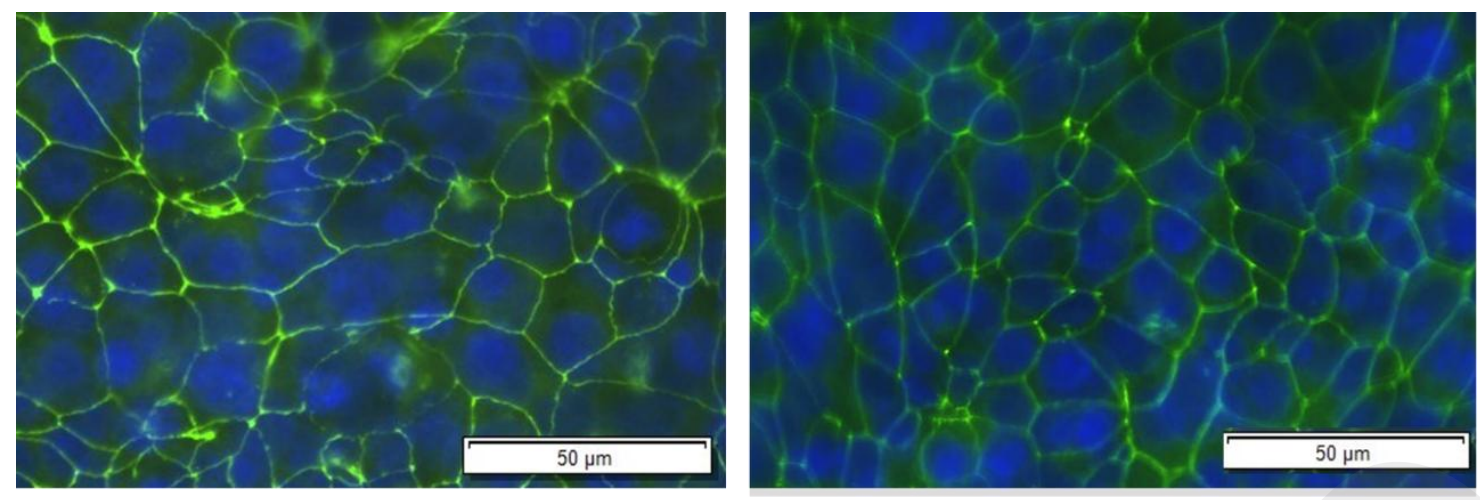


\section{TABLE LEGEND}

Table S1: Different immunsuppressive agents and serum trough levels that were used in the experiments.

Table S2: : Results of the EMT real-time PCR array for all the tested genes after $24 \mathrm{~h}$ or 4 days exposure to serum concentrations of MMF. Uncorrected $\mathrm{p}$ values are calculated using a Mann-Whitney U-test comparing cells without MMF exposure and cells with MMF exposure $(2.5 \mu \mathrm{g} / \mathrm{mL})$. Corrected $\mathrm{p}$ values were reached after correcting for multiple testing with a 'False discovery rate' test. A $p<0.05$ was considered significant. Fold upregulation is $>1$ when the gene of the MMF exposed cells is upregulated compared to the same gene in unexposed cells. Fold upregulation $<1$ when the gene of the MMF exposed cells is down regulated compared to the same gene in unexposed cells. Green indicates genes that are upregulated during EMT, red indicates genes that are down regulated during EMT. 
Table S1:

\begin{tabular}{|l|l|}
\hline Immunosuppressive agent & Levels used in the experiments \\
\hline Cyclosporine (C) & $0.3 \mu \mathrm{g} / \mathrm{mL}$ \\
\hline Tacrolimus (T) & $0.01 \mu \mathrm{g} / \mathrm{mL}$ \\
\hline Mycophenolate mofetil (MMF, M) & $2,5 \mu \mathrm{g} / \mathrm{mL}$ \\
\hline Azathioprine (A) & $0.5 \mu \mathrm{g} / \mathrm{mL}$ \\
\hline Dexamethasone (D) & $2 \mu \mathrm{g} / \mathrm{mL}$ \\
\hline
\end{tabular}


Table S2:

\begin{tabular}{|c|c|c|c|c|c|c|}
\hline \multirow[t]{2}{*}{ Gene } & \multicolumn{3}{|c|}{ 24h exposure } & \multicolumn{3}{|c|}{4 days exposure } \\
\hline & Uncorrected $p$ & Corrected $\mathrm{p}$ after FDR & Fold upregulation & Uncorrected $p$ & Corrected $\mathrm{p}$ after FDR & Fold upregulation \\
\hline AHNAK & 0.11 & 0.42 & 0,67 & $0.05^{*}$ & 0.14 & 0,44 \\
\hline AKT1 & 0.45 & 0.78 & 1,19 & $0.08^{\#}$ & 0.21 & 0,64 \\
\hline BMP1 & 0.63 & 0.98 & 1,15 & 0.11 & 0.26 & 0,56 \\
\hline BMP2 & NA & NA & NA & $0.0004^{*}$ & $0.008^{*}$ & 23,41 \\
\hline BMP7 & NA & NA & NA & $0.006^{*}$ & $0.04^{*}$ & 5,03 \\
\hline CALD1 & $0.09^{\#}$ & 0.42 & 2,20 & $0.009 *$ & $0.05^{*}$ & 2,52 \\
\hline CAMK2N1 & $0.06^{\#}$ & 0.33 & 1,70 & $0.002 *$ & $0.03^{*}$ & 2,48 \\
\hline CAV2 & 0.88 & 1 & 0,96 & 0.70 & 0.75 & 0,95 \\
\hline $\mathrm{CDH} 1$ & 0.21 & 0.53 & 1,45 & 0.60 & 0.68 & 1,15 \\
\hline $\mathrm{CDH} 2$ & 0.56 & 0.89 & 1,25 & $0.03^{*}$ & $0.09^{\#}$ & 3,77 \\
\hline COL1A2 & NA & NA & NA & 0.15 & 0.31 & 0,55 \\
\hline COL3A1 & 0.95 & 1 & 1,03 & 0.34 & 0.54 & 3,86 \\
\hline COL5A2 & 0.47 & 0.81 & 1,26 & $0.02^{*}$ & $0.08^{\#}$ & 2,98 \\
\hline CTNNB1 & 0.30 & 0.58 & 1,80 & 0.70 & 0.75 & 0,93 \\
\hline DSC2 & 0.28 & 0.58 & 1,32 & $0.03^{*}$ & $0.09^{\#}$ & 0,57 \\
\hline DSP & 0.20 & 0.53 & 1,27 & 0.84 & 0.87 & 0,95 \\
\hline EGFR & 0.88 & 1 & 0,97 & 0.73 & 0.77 & 0,92 \\
\hline ERBB3 & 0.97 & 1 & 1,01 & $0.06^{\#}$ & 0.17 & 0,51 \\
\hline ESR1 & NA & NA & NA & 0.42 & 0.57 & 2,14 \\
\hline F11R & 0.73 & 1 & 1,07 & $0.03^{*}$ & 0.11 & 0,55 \\
\hline FGFBP1 & $0.01 *$ & 0.18 & 0,45 & $0.003 *$ & $0.03^{*}$ & 0,14 \\
\hline FN1 & 0.13 & 0.42 & 1,28 & 0.51 & 0.64 & 0,84 \\
\hline FOXC2 & 0.92 & 1 & 0,96 & 0.009* & $0.05^{*}$ & 3,53 \\
\hline FZD7 & $0.03^{*}$ & 0.24 & 1,76 & 0.72 & 0.77 & 0,93 \\
\hline GNG11 & 0.26 & 0.56 & 0,80 & 0.96 & 0.97 & 0,99 \\
\hline GSC & NA & NA & NA & 0.49 & 0.62 & 1,86 \\
\hline GSK3B & 0.67 & 1 & 0,91 & 0.44 & 0.59 & 0,89 \\
\hline IGFBP4 & 0.31 & 0.58 & 1,25 & 0.41 & 0.57 & 1,29 \\
\hline IL1RN & 0.77 & 1 & 1,10 & 0.59 & 0.68 & 1,08 \\
\hline ILK & 0.91 & 1 & 0,98 & $0.05^{*}$ & 0.14 & 0,60 \\
\hline ITGA5 & 0.86 & 1 & 0,97 & $0.03 *$ & $0.09^{\#}$ & 0,52 \\
\hline ITGAV & $0.004 *$ & 0.18 & 1,98 & $0.04^{*}$ & 0.14 & 0,63 \\
\hline ITGB1 & 0.85 & 1 & 0,93 & $<0.0001^{*}$ & $0.003 *$ & 0,66 \\
\hline JAG1 & $0.03^{*}$ & 0.24 & 1,46 & 0.56 & 0.67 & 1,15 \\
\hline KRT14 & 0.21 & 0.53 & 1,56 & $0.01^{*}$ & $0.054^{\#}$ & 0,30 \\
\hline KRT19 & 0.42 & 0.76 & 0,79 & 0.53 & 0.65 & 1,15 \\
\hline KRT7 & 0.71 & 1 & 1,10 & 0.65 & 0.73 & 1,11 \\
\hline MAP1B & $0.04 *$ & 0.28 & 1,88 & $0.0004^{*}$ & $0.008^{*}$ & 3,35 \\
\hline MMP2 & 0.12 & 0.42 & 1,50 & $0.08^{\#}$ & 0.21 & 0,61 \\
\hline MMP3 & 0.83 & 1 & 0,94 & $0.001 *$ & $0.02 *$ & 4,34 \\
\hline MMP9 & $0.02 *$ & 0.20 & 1,83 & 0.46 & 0.60 & 1,12 \\
\hline MSN & 0.36 & 0.67 & 0,75 & 0.37 & 0.56 & 0,08 \\
\hline MST1R & 0.37 & 0.67 & 1,23 & 0.18 & 0.35 & 0,75 \\
\hline
\end{tabular}




\begin{tabular}{|c|c|c|c|c|c|c|}
\hline NODAL & 0.12 & 0.42 & 1,61 & 0.40 & 0.57 & 0,63 \\
\hline NOTCH1 & 0.78 & 1 & 1,09 & 0.34 & 0.54 & 1,46 \\
\hline NUDT13 & 0.22 & 0.53 & 1,56 & 0.13 & 0.28 & 0,51 \\
\hline OCLN & 0.92 & 1 & 1,03 & 0.29 & 0.48 & 1,17 \\
\hline PDGFRB & 0.25 & 0.56 & 1,43 & 0.16 & 0.31 & 2,48 \\
\hline PLEK2 & 0.12 & 0.42 & 1,41 & $0.004^{*}$ & $0.04^{*}$ & 1,46 \\
\hline DESI1 & 0.16 & 0.47 & 1,43 & $0.008^{*}$ & $0.05^{*}$ & 1,73 \\
\hline PTK2 & 0.64 & 0.98 & 0,91 & 0.86 & 0.88 & 0,97 \\
\hline PTP4A1 & 0.16 & 0.47 & 1,28 & 0.24 & 0.41 & 1,15 \\
\hline RAC1 & 0.30 & 0.58 & 1,24 & 0.18 & 0.35 & 1,17 \\
\hline RGS2 & $0.04^{*}$ & 0.26 & 4,82 & $0.003^{*}$ & $0.03^{*}$ & 6,44 \\
\hline SERPINE1 & 0.26 & 0.56 & 1,52 & 0.13 & 0.28 & 1,76 \\
\hline GEMIN2 & $0.02^{*}$ & 0.20 & 1,72 & 0.11 & 0.26 & 1,42 \\
\hline SMAD2 & 0.52 & 0.87 & 1,15 & 0.38 & 0.57 & 0,89 \\
\hline SNAI1 & 0.22 & 0.53 & 2,04 & 0.46 & 0.60 & 0,79 \\
\hline SNAI2 & $0.02 *$ & 0.23 & 2,24 & $<0.0001^{*}$ & $0.003^{*}$ & 3,82 \\
\hline SNAI3 & 0.90 & 1 & 1,03 & 0.69 & 0.75 & 1,09 \\
\hline SOX10 & 0.13 & 0.42 & 2,21 & 0.35 & 0.54 & 0,54 \\
\hline SPARC & 0.25 & 0.56 & 1,30 & $0.02 *$ & $0.09^{\prime \prime}$ & 0,43 \\
\hline SPP1 & 0.83 & 1 & 1,08 & 0.97 & 0.97 & 1,02 \\
\hline STAT3 & 0.56 & 0.89 & 1,12 & 0.57 & 0.67 & 0,89 \\
\hline STEAP1 & 0.14 & 0.42 & 2,70 & 0.11 & 0.26 & 1,76 \\
\hline TCF3 & 0.12 & 0.42 & 1,20 & 0.19 & 0.35 & 1,33 \\
\hline TCF4 & 0.86 & 1 & 1,04 & 0.41 & 0.57 & 0,86 \\
\hline TFPI2 & $0.009 *$ & 0.18 & 3,80 & $0.01^{*}$ & $0.054^{\#}$ & 2,65 \\
\hline TGFB1 & 0.29 & 0.58 & 1,24 & 0.35 & 0.54 & 0,81 \\
\hline TGFB2 & 0.75 & 1 & 0,93 & 0.13 & 0.29 & 1,13 \\
\hline TGFB3 & 0.20 & 0.53 & 1,58 & 0.25 & 0.41 & 0,59 \\
\hline TIMP1 & $0.02 *$ & 0.20 & 1,44 & 0.64 & 0.73 & 1,04 \\
\hline TMEFF1 & $0.006^{*}$ & 0.18 & 0,44 & $0.004^{*}$ & $0.03^{*}$ & 0,63 \\
\hline TMEM132A & $0.09^{\#}$ & 0.42 & 1,69 & $0.05^{*}$ & 0.14 & 0,66 \\
\hline TSPAN13 & $0.07^{\#}$ & 0.38 & 1,56 & $0.02^{*}$ & $0.08^{\#}$ & 1,25 \\
\hline TWIST1 & 0.54 & 0.89 & 1,17 & 0.52 & 0.65 & 0,89 \\
\hline VCAN & NA & NA & NA & 0.18 & 0.34 & 2,23 \\
\hline VIM & 0.009* & 0.18 & 2,56 & $0.003^{*}$ & $0.03^{*}$ & 12,70 \\
\hline VPS13A & 0.13 & 0.42 & 1,52 & 0.40 & 0.57 & 0,83 \\
\hline WNT11 & NA & NA & NA & 0.11 & 0.26 & 5,00 \\
\hline WNT5A & NA & NA & NA & 0.20 & 0.35 & 2,62 \\
\hline WNT5B & $0.09^{\#}$ & 0.42 & 0,78 & 0.19 & 0.35 & 0,71 \\
\hline ZEB1 & NA & NA & NA & $0.009 *$ & $0.05^{*}$ & 6,01 \\
\hline ZEB2 & 0.99 & 1 & 1,00 & 0.14 & 0.30 & 0,61 \\
\hline
\end{tabular}

